\title{
The Critical Period of L2 Acquisition Studies: Implications for Researchers in Chinese EFL Context
}

\author{
Wuhan Zhu \\ School of English, the University of Sheffield, UK \\ Email: zhuwuhan@sina.com
}

\begin{abstract}
This paper reviews the studies centring on the Critical Period Hypothesis (CPH), the major contributor to early $\mathrm{L} 2$ instruction in China. It firstly finds out that, in recent studies of $\mathrm{CP}$ in $\mathrm{L} 2$ acquisition settings (roughly after the year of 2000); a lot more variables besides the age factor have been integrated. The critical period studies in L2 settings has triggered diverse and even competing versions; while in Chinese EFL context, the critical period studies are still in its initial stage, i.e., concentrating on Ages of Onset (AOs) . The paper thus points out the implications of the CP studies in $\mathrm{L} 2$ settings for researches in Chinese EFL context.
\end{abstract}

Index Terms-CPH, L2 settings, Chinese EFL context

\section{INTRODUCTION}

With the development of China' revolution and opening up to the world, English education has become extremely hot in China. As a result of China's entry into WTO, successful performance of Beijing 2008 Olympic Games and Shanghai 2010 World Exhibition, the number of people studying English, according a report from Beijing News report on 12 March, 2010, has surged to about 400,000,000. On the other hand, Chinese Ministry of Education issued a document as early as in 2001 to call for students staring English studies from the third grade in elementary schools in all cities and those villages which has the capability of teaching English. In some mega cities like Shanghai, the students were even required to study English from Grade one in primary school from the year of 2003. Until present, more and more children have begun to study English in kindergarten and even many kindergartens have turned into bilingual kindergartens. In addition, the market of early English language training has been greatly expanded.

Proponents of early English instruction in China are generally based on their belief "the younger=the better" in a critical period of L2 learning. The term critical period for language acquisition refers to "a period of time when learning a language is relatively easy and typically meets with a high degree of success. Once this period is over, at or before the onset of puberty, the average learner is less likely to achieve native-like ability in the target language" (Marinova-Todd et al., 2000, p.9). It is theoretically based on the Critical Period Hypothesis, which was in particular trigged by Lennerberg (1967) and was originally used to explain why children master the L1 within a remarkably short period of time and why adults can no longer learn a language as easily and as gracefully as children.

The fanaticism on early English instruction and learning from all levels in Chinese society seems to indicate that the $\mathrm{CPH}$ has been widely accepted in China. However, through the subsequent review in this paper, it finds out that scholars in Chinese academic world are sceptical to it because they have realized that the $\mathrm{CPH}$, from the day when it came into being, has been full of dispute. Myriads of researches of it have been done in L2 settings and the results are diverse. Unfortunately, the studies of the CPH in Chinese EFL context are far from enough and are still in its initial stage. Therefore, it is necessary to conduct a comprehensive review on the CPH studies in L2 settings, especially the CPH in recent period, to help gain a deeper insight and fully understand their implications on the studies in Chinese EFL context.

In realizing the aforementioned research aims, this paper at first discusses the original formulation of the $\mathrm{CPH}$ and then reviews the previous studies on $\mathrm{CPH}$ in second language settings. The review is divided into two periods: early studies before the year of 2000 and recent studies after the year of 2000. The justification of this division is that the main cause of the quarrel in early studies is from the partial standard of language, less concern with other variables, and from few perspectives and dimensions. These problems are solved by recent studies after the year of 2000. In addition, since mountains and mountains of researches have been done on the CPH studies, the new trend is more urgently to be reviewed for the new conditions of the $\mathrm{CPH}$ studies in China. The paper then reviews the studies of $\mathrm{CPH}$ in $\mathrm{Chinese}$ EFL context and points out the deficiencies. Based on the review, the implications from the studies of the CPH in L2 settings for the studies in Chinese EFL context are argued. At last of this paper, some conclusions are drawn.

\section{FORMUlation OF CPH AND POSITIONS TAKEN By SOME EARLY RESEARCHERS OUTSIDE CHINA}

This chapter first explores the originality of the theory of $\mathrm{CPH}$ and its link to second language acquisition and then 
categorizes the two opposing positions held by some early studies. Here 'early' means years before 2000. At last, it assesses the two positions and reveals the problems which call for being further studied.

\section{A. Original Formulation of the CPH and Its Link to SLA}

The CPH was well known for L1 acquisition originally, but it has aroused considerable interest on its effects on second language acquisition (SLA). Researchers in SLA field seem to have more interest in whether the CPH can be applied into SLA studies.

The CPH was first proposed by Montreal neurologist Wilder Penfield and co-author Lamar Roberts in a 1959 paper Speech and Brain Mechanisms, and was popularised by Eric Lenneberg in 1967 with Biological Foundations of Language. Lenneberg proposed brain lateralisation at puberty as the mechanism that closes down the brain's ability to acquire language. He claimed that:

automatic acquisition from mere exposure to a given language seems to disappear [after puberty], and foreign languages have to be taught and learned through a conscious and labored effort. Foreign accents cannot be overcome easily after puberty. However, a person can learn to communicate at the age of forty. This does not trouble our basic hypothesis [ . . . . (Lenneberg, 1967, p.176)

Based on the above quotations, research in SLA field was centred around age restrictions on the possibility of reaching native-like levels in an L2. According to Long (1990) and Birdsong (1999), research questions in SLA study are mainly categorized into the following three issues:

(1)Whether young language-learners are 'better' at learning a second language;

(2) Whether late learners can achieve native-like L2 proficiency; and

(3) Whether the turning-point age is around puberty.

According to these three issues, researchers put that the $\mathrm{CPH}$ is able to applied into the L2 acquisition field study on the condition that one of the following three conditions are met:

(1) Young language learners are better at learning a second language than adults.

(2) Learners who begin their L2 learning before critical period (CP) can achieve native-like L2 proficiency while adults cannot.

(3) There is a discontinuity of L2 learning for the learners who begin learning after CP.

\section{B. Diverse Positions of the Early Researches: Focusing on the Three Issues}

Following the three issues, a large number of studies were conducted. Some famous studies, especially from the 1970s to the year of 2000, are categorized in Table 1. These studies fall into two opposite positions: supporting the CPH or challenging it.

TABLE1.

TWO POSITIONS OF SOME EARLY STUDIES ON THE CPH

\begin{tabular}{|l|l|}
\hline \multicolumn{1}{|c|}{ Challenges of the CPH } & \multicolumn{1}{|c|}{ Support for the CPH } \\
\hline Asher, et al., 1969; Bialystok \& Hakuta, 1994, 1999; & Cochrane, 1980; Cummins, 1981; Hyltenstam, 1992; Johnson \\
Birdsong, 1992, 1999; Bongaerts, 1999; Coppieters, 1987; $\&$ Newport, 1989; McLaughlin , 1977;Oyama, 1976, \\
Fathman, 1975; Flege, 1995, 1999;Hoefnagel-HoËle \& & $\begin{array}{l}\text { 1978;Patkowski, 1980; Scovel, 1988; Walburg et al., } \\
\text { Snow, 1977; Moyer, 1999; Olson \& Samuels, 1973 }\end{array}$ \\
\hline
\end{tabular}

It seems not possible to specify all the studies one by one. Therefore, only some of these are chosen to represent how the studies were deployed to challenge or support the three points.

1. Positions on whether younger equals better. Several studies challenged the position that younger equals better. These studies compared younger and older learners in terms of their achievement in second language acquisition. The methodologies used in these studies included a range of designs from experimental studies with very brief acquisition periods (a few minutes to a number of weeks or months) (e.g. Olson \& Samuels, 1973; Snow \& Hoefnagel-Hoehle, 1977) to naturalistic studies with acquisition periods of up to one year, as in the case of Snow \& Hoefnagel-Hoehle (1978). These have identified adults' advantage over children (Johnson \& Newport, 1989, etc.). As a result, the general younger= better hypothesis of the $\mathrm{CPH}$ was seen as falsified.

After reviewing the literature, Krashen et al. (1979) and Long (1990) point out that this category of studies actually had very little to do with the $\mathrm{CPH}$, because in reality they only investigated that older learners acquired certain aspects of their second language at a higher rate than the younger ones. They did not investigate the learners' eventual outcome. Furthermore, the lasting time of the subjects' residence and learning a foreign language was really too short. Therefore, they concluded the above studies did not pose any threat to the $\mathrm{CPH}$.

2. Positions on whether there exist native-like late learners. Some other studies challenging the $\mathrm{CPH}$ point out that there exist adults who achieve a native -like second language proficiency or native -like second language competence in grammaticality judgement, a question formation, pronunciation and other tasks (see review in Birdsong 1999). These studies identified learners with ages of onset (hereafter AOs) after puberty who eventually perform in the range of native speakers. Here are some examples. Birdsong (1992) discovered that 15 of his 20 late foreign language learners of French (L1 English) performed within the range of native speakers on a difficult grammaticality judgement task. In a similar manner, Bongaerts (1999) and his colleagues found out that some highly proficient Dutch foreign language 
learners of English and French with post-puberty AOs had native-like pronunciation. Further, White and Genesee (1996) adopted a strict screening procedure among a group of 99 advanced second language learners of English (L1 French) and identified 45 of the learners as near-native and the remaining 44 as nonnative. Both groups were then assessed with two measures, a grammaticality judgement test and a question formation test. Both tests investigated the accessibility to the Universal Grammar features of Subjacency and the Empty Category Principle. In connection with the grammaticality judgement test, reaction times were also measured. The results showed significant differences between the non-natives and a native control group, but no significant differences between the near natives and the native group, not even in reaction time.

However, as for the claim that there exist some native-like late learners, Hyltenstam and Abrahamsson (1992) reveal one weakness that may make the above studies a less serious threat to the CPH. That is, all of these studies compared advanced learners with native controls only in one or more single dimensions of the learners' L2. Furthermore, all of the authors referred to above noted themselves that even when subjects perform within the range of native speakers in the dimensions investigated, they may differ from native speakers in other respects (Birdsong, 1999).

3. Positions on whether the turning-point age is around puberty. Some other researches also challenged the $\mathrm{CPH}$ because they argue that an age effect on ultimate attainment is not obviously linked to any specific age span, such as before or after puberty, but has been demonstrated to be successive over the entire life-span. Bialystok and Hakuta (1994) and Flege (1999) have found a linear decline in eventual outcome with increasing AOs. Flege (1995) investigated 240 learners of English (L1 Italian) with AO 2-23, along with a group of native controls, who were rated for accent by native speakers of English. No discontinuity was found around puberty or any other age. Another example is Bialystok and Hakuta (1999) who analysed data from the 1990 U.S. population census. As many as approximately 25,000 L1 speakers of Chinese and 39,000 L1 speakers of Spanish were included in the study, all of whom had a length of residence (LOR) in the USA of more than 10 years. The subjects had self-rated their proficiency level in English on a five grade scale, and this rating was correlated with their calculated age of arrival. The results showed the expected pattern: the higher the age of arrival the lower the level of eventual proficiency. Bialystok and Hakuta conclude that the decline in proficiency remains constant across the ages and is similar for both Spanish and Chinese.

However, other researches support there exist a turning point in the process of L2 acquisition. Two different offset ages have been identified in different studies, one around puberty, which is then in accordance with Lennerberg's early hypothesis (Oyama, 1976; Patowski, 1980; Scovel, 1988) and one around 6-7 years of age, thus similar to Lennerberg's (Johnson \& Newport, 1989; Hyltenstam, 1992).

Oyama analysed the accent and listening comprehension of 60 second language speakers of English (L1 Italian) with AO 6-20 and their length of their residence (LOR) is from 5 to 18 years. In another study of this type, Patkowski studied the free oral production of 67 immigrants to the United States. Half of the subjects had started to acquire English before the age of 15, while the other half began acquisition after that age. The results of these two studies showed a strong effect for AO but not for LOR. Thus they support that the offset age is around puberty.

In the other study, Johnson \& Newport investigated the performance of 46 adult Chinese and Korean learners of English in the USA on measures of grammatical intuition. They found that learners who had arrived at ages 3-7 performed within the range of native controls. For learners who had arrived at ages between 7 through puberty, there was a linear decline in performance, while for those who had AOs above 17 the performance was not predictable from their AO. The authors concluded that the age effect is present during a time of ongoing biological and cognitive maturation and absent after maturation is complete (i.e. after puberty). Similar findings were also made in the study of Hyltenstam (1992). These studies show that native-like performance seems possible if learning starts before the age of 7. On the other hand, an AO after 7 does not seem to guarantee a native-like ultimate attainment. This means that the level of ultimate attainment is predictable for AOs up to a certain early age after which the correlation between AOs and ultimate attainment becomes random. So these studies are in principle in congruent with a $\mathrm{CPH}$, although they have put the offset at the lower age level which derivate from Lenneberg's original formulation of the $\mathrm{CPH}$ with regarding to the end point of the critical period.

4. Summary assessment of the early studies of $\mathrm{CPH}$ and problems to be further solved

a. Three problems in the early studies of $\mathrm{CPH}$. Based on the previous review, it is concluded that the debate on the $\mathrm{CPH}$ in SLA studies is fierce. There exist three problems to be solved.

(1) The studies which investigate the learners' eventual attainment of L2 learners, especially of adult learners whose AOs are after CP, are not enough. Meanwhile, they do not make a suitable interpretation to why older learners acquire certain aspects of their second language in higher rate than younger ones.

(2) The standard of 'nativeness' was not clear in these studies. There is no all-acknowledged parameter to test the language proficiency of learners. The parameters of competence or performance employed in the above studies are partial, not comprehensive.

(3) These studies have not achieved a consensus on whether there is a cut-off age point or a continuous decline, while this point is crucial to the CPH in SLA studies.

b. The most crucial problem of the early researches: partial methodology. Of the three problems illustrated above, the second problem needs to be highlighted here because it is very difficult for learners to have an all-acknowledged parameter to test the language proficiency of learners. This problem is actually attributed to the diverse theoretical 
linguistics on the definition of language. To make readers understand this kind of situation deeply, it is necessary to discuss the definition of language.

Chomsky (1957), leader of formalist linguistics, defines that language is united with competence and performance. In Chomsky's view, linguistic theory is not immediately concerned with describing the actual language use in a language community. Although it is assumed that there is a relation between the language users' grammaticality intuitions and their actual language behaviour, there is a sharp distinction between these. On the one hand, the language system may offer possibilities which are rarely or never used; on the other hand, the actual language use involves mistakes which a linguistic theory should not necessarily account for. In Chomsky's terminology: linguistics is concerned with the linguistic competence rather than the actual performance of the language user. However, functional linguists, represented by Halliday, are more concerned with performance. Halliday (1978) sees linguistic universals as a manifestation of the types of use to which we put a language, while language development is the product of learning how to communicate in face-to face interaction. In his view of linguistic universal, there is no need to treat it as innate.

The diverse definitions held by formalist and functionalist may naturally lead to a confusion of the eventual attainment of L2 learners. Moreover, it may cause an unclear parameter of native or near- native language for linguists have not common parameter, competence or performance, to be employed to measure the eventual attainment of L2 learners. Some researchers before the year of 2000 rely on a grammatical judgement to measure the competence of L2 learner, while other researchers rely on other measures categorized into performance. Table 2 demonstrates some of these studies before the year of 2000 .

TABLE2.

METHODOLOGIES OF SOME STUDIES

\begin{tabular}{|l|l|l|}
\hline Researches & Heavily rely on competence test & Heavily rely on performance Test \\
\hline Bialystok \& Hakuta (1999) & & Pronunciation \\
\hline Birdsong (1992) & grammaticality judgement & \\
\hline Bongaerts (19990 & & read-aloud task \\
\hline Flege (1995) & grammatical intuition & \\
\hline Johnson \& Newport (1989) & & five grade scale \\
\hline Oyama (1978) & & accent and listening comprehension \\
\hline Patkowski (1980) & & free oral production \\
\hline White \& Genesee (1996) & $\begin{array}{l}\text { a grammaticality judgement test, and a } \\
\text { question formation test }\end{array}$ & \\
\hline
\end{tabular}

These studies are manifestations of the diversion between formalist and functionalist. The methodologies are partial and thus inevitably lead to the quarrel on the eventual attainment of L2 learners. Luckily in the subsequent review, it is easily seen that recent researches (mainly after the year of 2000) have drawn lessons from the early researches and further studied the $\mathrm{CPH}$ from various linguistic aspects and dimensions. These recent studies have pushed a development of the CPH in SLA studies.

\section{FURTHER DEVELOPMENT OF THE CPH IN SLA STUDIES}

According to the problems calling for further studies, this part reviews recent studies and highlights the development compared with the early studies.

\section{A. Developmental Studies on Eventual Attainment of L2 Learners: Focus on Variability and More Aspects of Language}

According to the above review on the early studies which probe the eventual attainment of L2 learners and whether there are native-like learners, the results are in dispute. This is because researchers employed different standard to measure the learners' attainment, i.e., they partially relied on some parameters of competence or performance, and thus leading to diverse results.

Many new studies go beyond the scope of traditional inquiries as they apply mixed research methodology. Although these studies still use grammaticality judgment tests following Johnson and Newport's (1989) seminal study, they combine formal tests of competence with measures of performance and focus on wider variables (Bongerts et al., 1995, 1997; Marinova-Todd, 2003; Moyer, 2004; Nikolov, 2000; Urponen, 2004, etc.).

Three researches are specified here. In the study of Marinova-Todd (2003), it examined the profiles of 30 post-puberty learners of English from 25 countries and speaking 18 languages. The results were matched with a control group of 30 native speakers with academic backgrounds. Data were collected with the help of a number of formal tests and a narrative task. Formal tasks included a previously validated grammaticality judgment test, sentence comprehension tests, a standardized vocabulary test, a discourse completion test, reading out a paragraph, and spontaneous speech (Frog story with visual prompts) to evaluate pronunciation and fluency. According to the methodology of this research, it can be easily seen the greater progress has been achieved in contrast to the previous studies, which integrated grammatical judgement tests with various measures of performance.

The other study which needs to be highlighted here is by Moyer (2004), which studied not only the language proficiency of 25 successful well-educated immigrants to Germany from Britain, France, Poland, Russia, Slovakia, 
Turkey, and the U.S., but also explored how their ultimate attainment was influenced by their opportunities and intentions, thus integrating quantitative and qualitative data. Three sets of instruments were used for data collection: (1) a questionnaire surveying biological-experiential, social-psychological, instructional cognitive, and experiential-social experiences; (2) controlled and semi-controlled production tasks (reading out words, a paragraph, spontaneous speech on an important or embarrassing situation, recital of short sayings or proverbs); and (3)semi-structured interviews.

Nikolov (2000) conducted two parallel studies involving late starters of L2 English and Hungarian. Participants in the first study were 20 adults learning Hungarian, all of whom started learning the target language as young adults in Hungary. The second study involved 13 Hungarians. All of them started English at the age of 15 in secondary school and some of them studied one or two semesters abroad as young adults. Both studies involved control groups of native speakers. Data were collected using three instruments: (1) participants' background was explored with the help of structured interviews; (2) a narrative task in which they were asked to describe an embarrassing moment in their life or a happy moment they remembered with pleasure; (3) they read out an authentic passage in the target language.

To sum up, three more implications will be drawn from the above studies:

(1) An important development in these studies relates to the variety of first and target languages: Successful post-puberty learners of L2 English, German, and Hungarian were involved speaking over 30 languages as L1, for example, Bulgarian, English, Farsi, Finnish, French, Hungarian, Russian, Slovak, and Ukrainian, among others.

(2) These recent studies tap into a number of variables especially on the learner variables such as "opportunities afforded to individual learners" (Moyer, 2004,) and the extent to which they wish to be taken for native speakers. An important finding relates to the status and perception of languages, because learners 'first language and culture and the L2 and culture also exert an influence on ultimate attainment: in Moyer's (2004) study an American participant learning German, and in Nikolov's (2000) research three Russian wives and a British woman learning Hungarian did not want to pass for L2 native speakers, for they considered their accent to be an integral part of their identities and their culture of higher prestige. These findings are in line with what Moyer (1999) found in her previous study in which few successful advanced learners of German wanted to be sound native or even to improve their phonology. However, a Ukrainian speaker of German (Moyer, 2004), and a young Russian entrepreneur and a Bulgarian actress speaking Hungarian (Nikolov, 2000) did not wish to be identified by their accent and worked on their language development consciously.

(3) A similar result has got in the recent studies that later learners could achieve native-like foreign language proficiency. For example, in the study by Marinova-Todd (2003), three main profiles emerged for highly proficient late learners: (1) Three women, married to native speakers of English, attained native level across all domains. (2) Two participants (also married to native speakers of English) were within native range on all measures, but in receptive vocabulary. (3) Three other women, none of whom lived with native speakers of L2, achieved similarly high scores on all tests, but they failed on both measures of pronunciation. So these studies clearly demonstrate that native ultimate attainment is available to a number of adults who started learning the target language after puberty, therefore, the strong version of the CPH cannot be maintained any longer.

\section{B. Recent Studies on Discontinuity}

The question whether a cut-off point or a continuous decline characterizes learners in second language contexts is pivotal to the $\mathrm{CPH}$ debate. A critical period for language learning is often defined as a sharp decline in learning outcomes with age. Hakuta, Bialystok and Wiley (2003) tested the CPH on data from the 1990 U.S. Census using self-assessments on age on arrival, length of exposure, and language development from 2.3 million immigrants with Chinese and Spanish L1. Instead of finding a markedly different line regressing on either side of the CP, their results showed large linear effects for level of education and for age on arrival. This lack of discontinuity indicates "that the degree of success in SLA steadily declines throughout the life span".

Chiswick, Lee and Miller (2004) analyzed a huge dataset in a longitudinal survey of immigrants to Australia. These studies failed to find a pattern of discontinuous decline indicating a hallmark of a critical period. MacWhinney(2005) explains the absence of a sharp decline and age-related effects within his Unified Competition Model: older learners become increasingly reliant on connections between sound and orthography and they vary in the constructions they can control or that are missing or incorrectly transferred. They are also affected by restricted social contacts and declining cognitive abilities. In his view, none of these factors predict a sharp drop at a certain age in L2 learning abilities, but a gradual decline across the life span. An in-depth analysis of maturational constraints is put forth by Hyltenstam and Abrahamsson (2003) arguing that a "consensus model" can integrate the accumulated evidence on empirical facts and the relationships among them. In their view, maturation can account for the general linear decline in learning potentials with increasing age on arrival for learners in general, "whereas the variability between exceptionally successful and non exceptional L2 learners of the same starting age is accounted for best by non maturational factors".

Barry and Paul (2008) also examine the relevance of the critical period for English-speaking proficiency among immigrants in the USA. It uses micro-data from the 2000 US Census, a model of language acquisition and a flexible specification of an estimating equation based on 64 age-at-migration dichotomous variables. Self-reported English-speaking proficiency among immigrants declines more or less monotonically with age at migration, and this relationship is not characterised by any sharp decline or discontinuity that might be considered consistent with a 'critical' period. 


\section{Summary}

After reviewing the recent studies, it is clearly to be found that these new studies go beyond the scope of traditional inquiries and combine formal tests of competence with measures of performance. They seek to investigate more and more variables concerned with CPH, especially on learners' factors such as first languages and their cultures, learner' level of education and the age of arrival at a foreign culture, different target language, etc.

\section{CPH STUDIES IN CHINA}

The Critical Period Hypothesis seems to have been widely acknowledged by educational policy makers of Chinese government and people from different level of societies. However, in contrast to the fanaticism from these people, the academic world has been prudent and even sceptical to the critical period of L2 acquisition. Several empirical studies have been done to test the hypothesis and the results are diverse.

Compared with myriads of empirical studies of the CP outside China, the CP studies in China are still staying in their initial stage. Specifically, much more speculative analysis and reviews of the CPH (Dai, 1994; Wang, 2001; Hu, 2002; Zhao, 2002; Liu, 2003; Ding, 2004; Yang, 2004; to name but just a few) were done than empirical studies in China. Nearly all the scholars have shown their cautious attitude to the CPH. This is because they realized that the research on the CPH has primarily concentrated on learners in L2 setting, in which learners get access to L2 outside the classroom and are immersed in the context where the L2 is used as a main communicational tool. In China, learners have very limited access to English outside classrooms. So it is too rash to use the CPH to serve in Chinese EFL context. Ding (2004) was sceptical to the CPH from cultural perspective. He thinks that the CPH hypothesis was first put forth in developed western countries and studied under the environment of western culture. The educational practice influenced by this culture tends to emphasize the importance of letting individual learners work at their own pace, without pressure from outside. Under this culture, people believe that L2 development will take place naturally by itself even without much effort as long as learners are exposed to L2 data frequently.

The Chinese culture, in contrast, lays emphasis on social organization and on the need of individuals to cohere and contribute to the organization. Learners under the Chinese educational system, in other words, are not to become 'what they might be', but what they needed to be. This tradition justifies, in Chinese educational practice, the pressure on learners and the importance attached to their hard, conscious effort. Therefore, Chinese educators look at the existence of CPH with deep suspicion when they teach pupils 'no pains, no gains.'

In comparison with the number of speculative analysis of the critical period of L2 acquisition, few empirical studies (Dong, 2003; Wang, 2003; Shu, 2003; Lu, 2004; Liu, 2005; Xin \& Zhou 2006; Zhao \&Zou, 2008) have been found in Chinese EFL context.

The results of these empirical studies are diverse; however, more studies support that no critical period determines success in learning English in Chinese EFL context. For example, Zhao and Zou (2008) conducted a qualitative analysis of 42 autobiographies of contemporary renowned foreign language experts in China to examine the age related factors that may have led to success in foreign language learning. The study demonstrates a moderate correlation between AO and self-assessed achievements in the whole database of early-starters and late-starters and a weak correlation found in the early-starters. This finding does not support the CPH and argues that the other important factors such as motivation, teachers and language aptitude may decide L2 success for the learners. Wang (2003) performed a similar survey of the language learning experiences of some 30-well known scholars in the field of EFL, 11 successful English learners and a number of students learning German on an intensive training course at a Chinese famous university. The result shows that there does not really exist a so-called optimum age for Chinese learners. The author thus proposes that a strong motivation, proper learning strategies and intense efforts are decisive factors in successfully learning a foreign language.

Among the empirical studies which resulting in opposing the CPH, Liu (2005) set a good example for Chinese researchers. He investigates the effects of early English learning in China, a language learning context often marked by a lack of sufficient input in English. About 800 participants were studied. This suggests that differences in teaching quality, and overall English environment, as well as possible the English exposure outside urban and rural schools play a more significant role in learner success. It suggests that the external conditions (e.g., class size, class time, facilities, and quality teaching) directly affect and shape our students' internal conditions (e.g., motivation, attitudes, anxiety, and inhibition) at the early stage of their English learning.

There are two similar empirical studies whose findings support the CPH in Chinese EFL context. Lu (2004) and Xin and Zhou( 2006) analyzed the influence of SLA beginning age on the postgraduates'English level and found a positive correlation between early starting age and these postgraduates' English proficiency. Thus they suggest that, the initial English program should be begun in elementary school rather than in junior high. In addition, the optimal timing for the program is not as early as possible. Grade 3 is a possible starting point, but Grade 4 or 5 may be more preferable. However, from our view point, these two empirical studies are hard to prove the existence of the CPH in Chinese EFL context. We may also judge that the external factors, such as the long exposure of English, the better teaching conditions for those graduates who start learning English in early age may lead to their higher proficiency than the other graduates.

\section{IMPLICATIONS OF THE CPH STUDIES FOR THE FUTURE STUDY IN CHINESE EFL CONTEXT}


In Compared with the huge amount of research of the CPH in language setting, there is still little research, especially empirical research in China. A lot more research is urgently called for in Chinese EFL context. On the other hand, the critical review of the studies of the $\mathrm{CPH}$ in L2 settings has offered much implication for future study in China. Three crucial implications are highlighted here.

\section{A. Testing the Language Proficiency of Chinese EFL Learners from Comprehensive Dimensions}

According to our review above, it cannot be denied that there is still no consensus on whether second language learners can achieve native language proficiency. However, the recent researches have gained much progress in measuring the L2 learners' language proficiency because they combine formal tests of competence with measures of performance and focus on wider variables.

An all-acknowledged parameter to test the language proficiency of learners seems to be difficult to be made. Therefore, a comprehensive parameter of competence and performance to test L2 learner' language performance is necessary. However, the empirical studies in Chinese EFL context have employed a very partial parameter. In Wang (2003) and Zhao and Zou's (2008) studies, the definition of successful learners are very fuzzy. Do the successful learners or scholars mean they are native-like English speakers? Do they exhibit a native-like English proficiency in all aspects of language? These problems which may shake the foundation of these two researches exist in the other studies. For example, in Lu (2004) and Xin and Zhou's (2006) studies, it is too hasty that they draw a conclusion that there is a critical period of L2 acquisition just according to the good performance of an oral test and a written test from the postgraduates.

In conclusion, it is worth emphasizing here that a comprehensive parameter to test the learners' English proficiency is urgently called for in China. Marinova-Todd (2003) set a good example (cf. the previous chapter for a detail). More studies on the features' of learner language are needed in China.

\section{B. Calling for More Empirical Studies on CPH from Different Factors}

Various factors of learning English, not limited in age factor, should be taken into consideration in China. Many Chinese scholars have paid attention to this. For example, Liu (2003) puts that the impact of other factors related on language acquisition need to be considered, instead of the age factor alone. However, empirical studies in Chinese EFL context have seldom taken these factors into consideration.

Although it has been extensively studied for several decades, CPH remains as controversial today as ever before. Although the standard of native-like language proficiency is fuzzy, some researchers claim that they could find cases that native-like competence is attainable after the critical period. Thus, individual differences are a powerful weapon used to compensate the shortcomings of CPH. Marinova-Todd et al. (2001) suggest that some factors other than age might be more crucial in successful L2 acquisition. Although older learners are indeed less likely than young children to master an L2, a close examination of studies relating age to language acquisition reveals that age differences in fact reflect differences in the context of learning (e.g., gettingL2 authentic input or language exposure) rather than in neurobiological abilities to learn.

In a word, the study of language is quite sophisticated, we need put more studies on individual differences on exploring how aptitude, attitudes, motivation, anxiety, and other factors contribute to outcomes over time. It would be useful to examine how young learners' cognitive abilities develop, how their L2 learning contributes to being open and friendly toward other cultures, and studying further languages. The role of the L1 has been neglected; therefore further research in Chinese EFL context is needed into how two or more languages interact with one another, and how children show developmental sequences typical of Chinese and the target language in different skills.

For pedagogical applications in Chinese EFL context, longitudinal studies are needed with a focus on the quality of the learning experience over time. It may integrate linguistic, cognitive, and affective factors contributing to young learners' development. It would be necessary to research case studies of both good and bad classroom practice: what children and teachers do in which language, how they interact with one another, how teachers scaffold children's development and what materials they apply and how peers contribute to classroom processes. In other words, it would be necessary to explore classroom practice over time and triangulate data collected from learners, teachers, and observers.

\section{Conducting the CPH Studies in Chinese EFL Context with Its Competing Version--from Socio-Cognitive Perspective}

CPH has become a coat of many colours (Singelton, 2005) that brings a large number of research areas of SLA together and does much deepen our understanding of the L2 learning process. It has become a medium through which different theories, even competing versions can be communicated. In the competing versions of the linguistics theories, the socio-cognitive linguistic theory is highlighted here because it is easily found from our review that the socio-cognitive factors of learners have actually been attached importance to in the previous researches in L2 settings.

Over the decades, critics on the CPH have never been silent. The sharpest one of them was from Swiss psychologist Jean Piaget (1955). According to Piaget and his associates, language acquisition takes place in the context of a child's intellectual development rather than as a separate growing progress. To Piaget, 'conceptualization precedes verbalization.' The ability to represent objects and events is prerequisite to the acquisition of language. The possibility 
of humans acquiring language turns into reality only when they need to communicate something. Many properties of language, in fact, are based on human experience in the word and therefore must be acquired as the child grows. From this point, the existence of the $\mathrm{CPH}$ is doubtful.

Piaget's theory was originally formulated and adopted in the first language acquisition studies. But it can be also used in the second language studies. As to the rate of second language acquisition, adults acquire primary levels of grammar more rapidly than young children because of their great cognitive abilities, with the exception of pronunciation. As for final attainment, however, children will prove much more successful. According to Piaget's theory, language learning can be seen as constant movement between the processes of hypothesis application and hypothesis reformulation, moving from knowledge to practice and back to knowledge again. In both processes, children are superior to their adult counterparts. First, children are not afraid of making mistakes and are more willing to take risks. Therefore, they are more ready than adult learners to put their hypothetical knowledge to the test of language practice. Second, they are more attentive to form, to how language, including minute features of language, is used in context. Since they make greater efforts to observe language use, they are more ready than adult learners to reformulate their L2 knowledge. And as the theory of identity (Burns, 1977) holds, children are strongly motivated to become part of the target language community, and it requires a native-like accent and a native-like competence to achieve this. In contrast, adults tend to be satisfied with a level of acceptable, functional L2 competence and tend to see no need for full linguistic integration.

Therefore, studies on the existence of the $\mathrm{CPH}$ in second language acquisition may possibly be conducted from cognitive perspective. The age difference can be explained from social-cognitive perspectives. This may answer the question why there exist so many different results to CPH researches. It may also explain why adults acquire certain aspects of second language at a higher rate than children in a short period after they begin to study a second language, due to the maturation of adult's cognition. In China, many scholars (e.g. Weng, 2008; Liu, 2010) speculate that socio-cognitive oriented L2 theories have laid a theoretical foundation for research of foreign language learning process learning motivations, learning strategies and socio-cultural factors in Chinese EFL context. Therefore, more empirical studies of the $\mathrm{CPH}$ in Chinese EFL context are expected to be conducted with the integration of socio-cognitive perspective in the future.

\section{CONCLUSIONS}

This paper discusses researches of the Critical Period Hypothesis (CPH) studies in L2 settings and Chinese EFL context. After surveying the early studies, it points out that the quarrel in the early studies was in fact due to the hot-disputed topic of the definition of language and studying from few perspectives. Thus, recent studies are more on different variables and combine competence and performance as the parameter. The paper further points out that the dispute on CPH in L2 studies will not be stopped and it needs to be further studied from multi-perspectives, especially from the social-congitive one. It thus will also lead SLA researchers to attend more studies to learner language. (eg. Hakuta et al., 2003; Hasselgreen, 2005; etc.) The CPH studies have brought much implication to the studies, especially empirical studies in Chinese EFL context.

\section{REFERENCES}

[1] Asher, J., \& Garcia, R. (1969). The optimal age to learn a foreign language. Modern Language Journal, 8, 334-341.

[2] Barry, R. C., \& Paul W. M. (2008). A Test of the Critical Period Hypothesis for Language Learning. Journal of multilingual and multicultural development, 29 (1), 16-29.

[3] Bialystok. E., \& Hakuta, K. (1994). In other words: The science and psychology of second-language acquisition. New York: Basic Books.

[4] Bialystok, E., \& Hakuta, K. (1999). Confounded age: Linguistic and cognitive factors in age differences for second language acquisition. Second language acquisition and the Critical period hypothesis, ed. D. Birdsong, 161-181.Mahway, NJ: Erlbaum.

[5] Birdsong, D. (1992). Ultimate attainment in second language acquisition. Language, 68, 706-755.

[6] Birdsong, D. (1999). Introduction: Whys and why nots of the critical period hypothesis for second language acquisition. Second language acquisition and the Critical period hypothesis. Ed. D. Birdsong, 1-22. Mahway, NJ: Erlbaum.

[7] Bongaerts, T., Planken, B., \& Schils, E. (1995). Can late starters attain a native accent in a foreign language: A test of the Critical Period Hypothesis. In D.Singleton \& Z. Lengyel (Eds.), The age factor in second language acquisition (pp. 30-50). Clevedon, Avon: Multingual Matters.

[8] Bongaerts, T., van Summeren, C., Planken, B., \& Schils, E. (1997). Age and ultimate attainment in the pronunciation of a foreign language. Studies in Second Language Acquisition, 19, 447-465.

[9] Bongaerts, T. (1999). Ultimate attainment in L2 pronunciation: The case of very advanced late L2 learners. Second language acquisition and the Critical period hypothesis, ed. D. Birdsong, 133-159. Mahway, NJ: Erlbaum.

[10] Burns, G. (1977). Introduction to group theory with applications. N. Y. Academic Press.

[11] Chiswick, B. R., Lee, Y. L., \& Miller, P. W. (2004). Immigrants' language skills: The Australian Experience in a longitudinal study. International Migration Review, 38(2), 611-654.

[12] Chomsky, N. (1957). Syntactic Structures. The Hague: Mouton.

[13] Chomsky, N. (1965). Aspects of the theory of syntax. Cambridge, MA: MIT press.

[14] Cochrane, R. 1980. The acquisition of /r/ and /l/ by Japanese children and adults learning English as a second language. Journal of Multilingual and Multicultural Development, 1, 331-360.

[15] Coppieters, R. (1987). Competence differences between natives and near-native speakers. Language, 63, 544-573. 
[16] Cummins, J. (1981). Age on arrival and immigrant second language learning in Canada: A reassessment. Applied Linguistics, $11,132-149$.

[17] Dai, M. (1994). On age difference in L2 acquisition. Foreign Language World, 2,18-22.

[18] Ding Y. (2004). Second Language Acquisition for English Majors. Shanghai: Shanghai Foreign Language Education Press.

[19] Dong, Y. (2003). Are We Ready for "an Early Start in Foreign Language Learning"? -A Survey of Primary School English Education in Guangdong Province. Modern Foreign Languages, 1, 39-47.

[20] Fathman, A. (1975). The relationship between age and second language learning productive ability. Language learning. 25(2), 245-53.

[21] Flege, J. (1995). Second language speech learning: Findings and problems. Speech perception and linguistic experience: Theoretical and methodological issues, ed. W. Strange, 233-277. Timonium, MD: York Press.

[22] Flege, J. (1999). Age of learning and second language speech. Second language acquisition and the Critical period hypothesis, ed. D. Birdsong, 101-131. Mahway, NJ: Erblaum.

[23] Halliday, M. (1978). Language as a social semiotic. London: Edward Arnold.

[24] Hakuta, K., Bialystok, E., \& Wiley, E. (2003). Critical evidence: A test of the critical period hypothesis for second-language acquisition. Psychological Science, 14, 31-38.

[25] Hasselgreen, A. (2005). Assessing the language of young learners. Language Testing, 22(3), 337-354.

[26] $\mathrm{Hu}$, M. (2002). My experience of foreign language learning and teaching. Journal of Foreign Languages, 5, 2-9.

[27] Hyltenstam, K. (1992). None-native features of near-native speakers. On the ultimate attainment of childhood L2 learners. Cognitive processing in bilinguals. Ed. R. Harris, 351-368. Amsterdam: Elsevier

[28] Hyltenstam, K., \& Abrahamsson, N. (2003). Maturational constraints in SLA. In C.J. Doughty \& M. H. Long (Eds.), Handbook of second language acquisition (pp. 539-588). London: Blackwell.

[29] Johnson, J., \& Newport, E. (1989). Critical Period effects in second language learning: The influence of maturational state on the acquisition of English as a second language. Cognitive Psychology, 21, 60-99.

[30] Krashen et al., (1979). Age, rate, and eventual attainment in second language acquisition. TESOL Quarterly, 13, 573-582.

[31] Lenneberg, E. (1967). Biological foundations of language. New York: Wiley \& Sons.

[32] Liu, J. (2005). Is Earlier Really Better? -A Report of a Study Investigating the Effects of Earlier English Education in China. China Foreign Language, 2(1), 14-21.

[33] Liu, Y. (2010).Two Epistemological Positions in the Construction of L2 Acquisition Theories: Implications for Research of Foreign Languages. China Journal of Northeast Normal University (Philosophy and Social Sciences), 4, 86-92.

[34] Liu, Z. (2003). A critique of the Critical Period in L2 acquisition. Contemporary Linguistics, 2, 158-172.

[35] Long, M. (1990). Maturational constraints on language development. Studies in second language acquisition. 12, $251-285$.

[36] Lu, X. (2004) The Critical Period Hypothesis and the Integrated Program of English Education. Foreign Language World, 1, 62-68.

[37] McLaughlin, P. (1977). Second language learning in children. Psychological Bulletin, 84,435-447.

[38] MacWhinney, B. (2005). A unified model of language development. In J. F. Kroll \& A. M. B. De Groot (Eds.), Handbook of bilingualism: Psycholinguistic approaches (pp. 49-67). Oxford: Oxford University Press.

[39] Marinova-Todd, S. H., Marshall, D. B., \& Snow, C.E. (2000). Three misconceptions about age and L2 learning. TESOL Quarterly, 34 (1), 9-34.

[40] Marinova-Todd, S. H. (2003). Comprehensive analysis of ultimate attainment in adult second language acquisition. Unpublished doctoral dissertation, Harvard University.

[41] Moyer, A. (1999). Ultimate attainment in L2 phonology. Studies in Second Language Acquisition, 21, 81-108.

[42] Moyer, A. (2004). Age, Accent and Experience in Second Language Acquisition. Clevedon: Multilingual Matters

[43] Nikolov, M. (2000). The CPH reconsidered: Successful adult learners of Hungarian and English. International Review of Applied Linguistics, 38, 109-124.

[44] Olson, L., \& Samuels, S. (1973). The relationship between age and accuracy of foreign language pronunciation. Journal of Educational Research, 66, 263-267.

[45] Oyama, S. (1976). A sensitive period for the acquisition of a nonnative phonological system. Psychological Research, 5, 261-285.

[46] Patowski, M. (1980). The sensitive period for the acquisition of syntax in a second language. Language Learning, 30, 449-472.

[47] Penfield, W., \& Roberts, L. (1959). Speech and Brain Mechanisms. Princeton: Princeton University Press.

[48] Piaget, J. (1955). The Construction of Reality in the Child, translated by Margaret Cook. Routledge and Kegan Paul.

[49] Scovel, T. (1988). A time to speak: A psychological inquiry into the Critical period for human speech. Newyork; Newbury House.

[50] Shu, D., Li,Z., \& Zhang, Y. (2003).An Investigation and Thinking of Primary School English Education in Shanghai. Foreign Language World, 3, 54-62.

[51] Singleton, D. (2005) The Critical Period Hypothesis: A coat of many colours. International Review of Applied Linguistics in Language Teaching. 43(4), 269-285.

[52] Snow, C., \& Hoefnagel-HoÈhle, M. (1977). Age differences in the pronunciation of foreign sounds. Language and Speech, 20, 357-365.

[53] Snow, C., \& Hoefnagel-HoÈhle, M. (1978). The critical period for language acquisition: Evidence from second language learning. Child Development, 49, 1114-1128.

[54] Urponen, M. I. (2004). Ultimate attainment in postpuberty second language acquisition. Unpublished doctoral dissertation. Boston University.

[55] Walburg, H., Hase. K., \& Pinzur, S. (1978). English acquisition as a distinguishing functions of experience rather than age. Tesol Quarterly, 12(4):427-437.

[56] Wang. B. (2003). Is there an onset age of Foreign Language Learning? Foreign Language World, 3,69-74.

[57] Wang. C. (2001). Research on the age factor in Second Language Acquisition. In Dong, Y. \&Wang, C. (eds.) Research and 
applications of Chinese Linguistics. Shanghai: Shanghai foreign education publishing house.

[58] Wen, Q. (2008). On the Cognitive-social Debate in SLA for More Than 20 Years. FLC, 5(3),13-20.

[59] White, L., \& Genesee, F. (1996). How native is near-native? The issue of ultimate attainment in adult second language acquisition. Second Language Research,12, 233-265.

[60] Xin, K., \& Zhou, k. (2006). Age factor on the Second Language Acquisition: An Empirical Study on the Critical Period Hypothesis. Foreign Language Education, 4, 80-82.

[61] Yamada, J., Takatsuka, S., Kotake, N., \& Kurusu, J. (1980). On the optimum age for teaching foreign vocabulary to children. International Review of Applied Linguistics in Language Teaching, 18, 245-247.

[62] Yang, L. (2004). The Critical Period Hypothesis and the Best Age in Second Language Acquisition. Foreign Language Research, 5, 101-106.

[63] Zhao, F., \& Zou, W. (2008). A narrative study of the age of onset and its implications for foreign language teaching. Modern Foreign Languages, 3, 317-326.

[64] Zhao, S. (2002). The Long Way of Acquiring a Foreign Language. Journal of Foreign Languages, 5,10-15.

Wuhan Zhu is currently a Doctoral Candidate in the School of English Literature, Language and Linguistics at the University of Sheffield in the UK. He received MA degree in English linguistics and a BA degree in English Education from Nanjing Normal University, China. He was a teacher of English and English linguistics in China and has published 7 papers in Chinese and international academic journals. His current interests include applied linguistics, pragmatics and cross cultural communication. 